\title{
Sutton's Law, Substance Use Disorder, and Treatment of Hepatitis $C$ in the Era of Direct-acting Antivirals
}

\author{
Allen L. Gifford, M.D. ${ }^{1,2,3}$ \\ ${ }^{1}$ Center for Healthcare Organization and Implementation Research (CHOIR), VA Boston Healthcare System, Boston, MA, USA; ${ }^{2}$ Section of General \\ Internal Medicine, Department of Medicine, Boston University School of Medicine, Boston, MA, USA; ${ }^{3}$ Department of Health Law, Policy, and \\ Management, Boston University School of Public Health, Boston, MA, USA.
}

J Gen Intern Med 35(4):988-9

DOI: $10.1007 / \mathrm{s} 11606-020-05654-\mathrm{Z}$

(c) Society of General Internal Medicine (This is a U.S. government work and not under copyright protection in the U.S.; foreign copyright protection may apply) 2020

$\mathrm{S}$ ubstance use disorder, in the present day and age, is broadly recognized as a chronic illness and a comorbidity - that is, a treatable comorbidity, not a behavioral preference, character flaw, or ethical lapse. But in many ways, we do not treat substance use disorder like other comorbidities. For example, effective treatments exist for opioid dependency and for alcohol dependency, but these treatments are woefully underutilized. And often people with substance use disorders face barriers accessing treatment for their other physical comorbidities as well, because they may be poor, marginalized, imprisoned, homeless, and/or stigmatized, and thus face societal difficulties accessing healthcare, just as they have difficulty accessing healthy food, housing, and social services.

But importantly, in some cases, clear written policies may also prevent or delay some types of care for people who use substances. When a treatment is expensive, complicated, or risky, payers and policy-makers have at times limited substance users' access - surgical valve replacement and transplant surgeries are examples. ${ }^{1-3}$ The rationale, either explicitly or implicitly, involves questioning whether those who are using illicit drugs can tolerate the hard work of getting through a difficult procedure, and afterward can change their behaviors to appropriately "take care of" their new organ, or new valve, and thus achieve a good outcome.

Treatment for hepatitis $\mathrm{C}$ virus (HCV) used to be arduous, involving a year of regular interferon injections and very difficult side effects, but now, all-oral direct-acting antivirals (DAAs) for HCV are a completely different situation. These medications are easy to take and highly effective, and have low toxicity. When introduced in 2013, they began a sea change in treatment of a highly significant and prevalent public health problem. Even so, many private payers and Medicaid programs put authorization criteria in place that explicitly restrict prescribing these medications to users of illicit drugs, alcohol, or both. ${ }^{4}$

Published online January 21, 2020
In this edition of the JGIM, Serper and colleagues present valuable data from a large observational "real-world" cohort of patients treated for HCV. They have largely put to rest longstanding concerns held by some clinicians and others that DAA treatment may not be fully effective in alcohol and substance users due to adherence difficulties. Instead, these investigators found that nonadherence, while it did occur, was modest (4\% and $8 \%$ early and late in treatment, respectively). But more importantly, actual HCV treatment failure was very rare (4\%) and was equal among adherent and nonadherent groups, and in those with and without alcohol and with and without substance use. In each of these key clinical categories, the sustained viral response (essentially viral cure) was greater than $95 \% .^{5}$ These data basically debunk any notion that in considering $\mathrm{HCV}$ treatment, nonadherence is an appropriate reason to place substance users at the back of the queue or away from the queue altogether. The finding, while important, will strike many as not surprising, given that DAA treatment courses are fairly short and the medications are easy to take.

Of course, policy constraints limiting prescribing by stage of liver disease or according to substance use behaviors or in any other way are actually driven by the high costs of DAA medications and the need to contain those costs. With its high wholesale sticker price, sofosbuvir, the first of the groundbreaking DAAs, was widely decried in the media and elsewhere as the "\$1000 pill." As the market for DAAs has matured and additional competing medications have come to market, costs have gone down, largely through privately negotiated purchase agreements involving pharmaceutical companies benefit managers, and insurance payers. Medicaid programs vary by state and are responsible for a great deal of $\mathrm{HCV}$ care. Although these and other entities clearly negotiate prices for DAAs that are well below sticker price, it is not possible to know specific prices paid. Researchers have combined available data and included assumptions about possible discounted drug costs, with results in most cases showing favorable cost-effectiveness ratios for DAA treatment (i.e., less than $\$ 100,000$ ), and in some analyses actual costsavings with DAA treatment. ${ }^{6,7}$

Though useful for societal perspective, these analyses still do not change the heavy impacts of HCV treatment costs on limited pharmaceutical budgets, nor do they factor in the "opportunity costs"-resources spent on $\mathrm{HCV}$, even if they 
are a good value, could be used to pay for other important healthcare or (in theory) societal problems. ${ }^{8}$ Until costs for DAA medications decrease substantially, likely to an order of magnitude much greater extent than they have done under the most favorable of privately discounted agreements, we will continue to struggle to make good clinical and policy decisions about how to prioritize which patients to treat for $\mathrm{HCV}$, and when.

But we can say that delaying treatment in substance users under the rationale that they are less likely than others to respond to treatment is the wrong answer. What's the way forward? Well, the overarching goal is to reduce and eliminate transmissible $\mathrm{HCV}$ at population levels, using the new, effective (albeit expensive) treatment tools we have at our disposal. These medications are of proven effectiveness in vulnerable populations that include substance users, and can be brought into clinical programs that also include other effective treatments for opioid, alcohol, and other dependencies. Using this sort of approach, there's a great deal to be said for applying Sutton's Law, learned and repeated by generations of physicians as "go where the money is." The "money"- $\mathrm{HCV}$ infection-exists in the social networks of substance users that are in our communities. Putting emphasis on substance users for treatment using effective clinical programs may be an opportunity for future success in $\mathrm{HCV}$ eradication, not a liability to be avoided, and this should be a consideration in making resource decisions about treatment of $\mathrm{HCV}$.

Corresponding Author: Allen L. Gifford, M.D.; Center for Healthcare Organization and Implementation Research (CHOIR), VA Boston Healthcare System, Boston, MA, USA (e-mail: allen.gifford@va.gov).

\section{REFERENCES}

1. General Considerations in Assessment for Transplant Candidacy [Reviewed in 2015]. Organ Procurement and Transplantation Network. https://optn.transplant.hrsa.gov/resources/ethics/general-considerations-in-assessment-for-transplant-candidacy/

2. Baddour LM, Wilson WR, Bayer AS, Fowler VG Jr, Tleyjeh IM, Rybak MJ, Barsic B, Lockhart PB, Gewitz MH, Levison ME, Bolger AF, Steckelberg JM, Baltimore RS, Fink AM, O'Gara P, Taubert KA: American Heart Association Committee on Rheumatic Fever, Endocarditis, and Kawasaki Disease of the Council on Cardiovascular Disease in the Young, Council on Clinical Cardiology, Council on Cardiovascular Surgery and Anesthesia, and Stroke Council. Infective Endocarditis in Adults: Diagnosis, Antimicrobial Therapy, and Management of Complications: A Scientific Statement for Healthcare Professionals From the American Heart Association. Circulation. 2015;132(15):1435-86. https://doi.org/10. 1161 /CIR.0000000000000296.

3. Minelli E, Liang BA. Transplant Candidates and Substance Use: Adopting Rational Health Policy for Resource Allocation. U. MICH. J. L. REFORM. 2011; 44(3):667-98.

4. Canary LA, Klevens RM, Holmberg SD. Limited Access to New Hepatitis C Virus Treatment Under State Medicaid Programs. Ann Intern Med. 2015;163(3):226-8. https://doi.org/10.7326/M15-0320.

5. Serper et al. Medication non-adherence in a prospective, multicenter cohort treated with hepatitis $\mathrm{C}$ direct-acting antivirals. J Gen Intern Med. https://doi.org/10.1007/s11606-019-05394-9.

6. Chhatwal J, He T, Hur C, Lopez-Olivo MA. Direct-acting antiviral agents for patients with hepatitis $\mathrm{C}$ virus genotype 1 infection are cost-saving. Clin Gastroenterol Hepatol. 2017;15(6):827-837.

7. AASLD/IDSA. Overview of Cost, Reimbursement, and Cost-Effectiveness Considerations for Hepatitis C Treatment Regimens [last update: November 6, 2019]. HCV Guidance: Recommendations for Testing, Managing, and Treating Hepatitis C. https://www.hcvguidelines.org/evaluate/cost/

8. Wong JB, Cohen JT. Cost-effective but bad for health? Hepatitis C treatment, moral hazard, and opportunity cost. Clin Gastroenterol Hepatol. 2017;15(6):838-840.

Publisher's Note Springer Nature remains neutral with regard to jurisdictional claims in published maps and institutional affiliations. 